\title{
Letter to the Editor Regarding: Continuous Glucose Monitoring in Type 2 Diabetes Mellitus Patients in Primary Care
}

\author{
Valerija Bralić Lang (D) - Maja Baretić
}

Received: May 4, 2019 / Published online: January 29, 2020

(C) The Author(s) 2020

Keywords: Continuous glucose monitoring; Primary care; Type 2 diabetes mellitus

\begin{abstract}
Dear Editor,
It was very interesting to read the manuscript "Continuous glucose monitoring: a brief review for primary care practitioners" written by Ajjan et al. [1] on the topic of continuous glucose monitoring (CGM). As claimed in the paper published in Advances in Therapy, data on CGM use in type 2 diabetes mellitus (T2DM) (especially without insulin therapy, which is the most prevalent in primary care) are scarce. So, we decided to share our own experience based on a previously conducted study that was approved by The Medical Ethics Committee of the Medical School, University of Zagreb and all participants gave informed consent.

In our study 20 primary care practitioners (PCP) recruited 100 patients with T2DM treated with oral antidiabetics. The median (min-max) age of PCPs, working experience, number of enlisted patients, T2DM in care, and daily visits
\end{abstract}

\footnotetext{
V. Bralić Lang $(\bowtie)$

Private Family Physician Office Affiliated to the Department of Family Medicine, University of Zagreb, School of Medicine, Zagreb, Croatia e-mail: valerija.bralic.lang@gmail.com

M. Baretić

Department of Endocrinology, University Hospital Center Zagreb, Zagreb, Croatia
}

were $51.5(42-62)$ years, $26(16-36)$ years, 1980 (1550-2100) patients, 139 (48-318) patients, and 73 (66-82) patients/day, respectively. Patients were monitored with a professional CGM device (iPro ${ }^{\mathrm{TM}} 2$ Medtronic; sensor life 6 days). Both the patient and physician were blinded for the CGM data until after the data were downloaded. Indications for CGM were clinical suspicion of hypoglycemia $(30 \%)$ or disproportion between actual levels of glycemia and A1C levels (70\%). A total of 41 male and 59 female patients with T2DM and a median age of 65 years (range 40-86) were included in the study. At recruitment the median hemoglobin A1C, age, T2DM duration, and body mass index of the patients were $7 \%$ (5.7-11.5\%), 65 (40-86) years, 7 (1-36) years, and 30.04 $(21.30-41.45) \mathrm{kg} / \mathrm{m}^{2}$ respectively. The majority of patients $(74 \%)$ were treated with one $(33 \%)$ or two $(41 \%)$ oral hypoglycemic drugs while three agents were used in 23\% and four in 3\% of patients. Metformin was used in $90 \%$, sulfonylurea in $49 \%$, pioglitazone in $13 \%$, dipeptidyl peptidase 4 (DPP4) inhibitors in 35\%, and sodium/glucose cotransporter 2 (SGLT2) inhibitors in $7 \%$ of patients.

CGM data of 94 patients were analyzed. CGM of six participants revealed no data: in four cases the sensor itself was not applied properly (probably because of poor durability of the adhesive used for attachment of the sensor to the skin during extremely hot summer days) 
and in two cases there was no record on the system upload for no obvious reason. A total of 38 participants had at least $1 \%$ of time and/or blood glucose area under the curve (AUC) below $3.9 \mathrm{mmol} / \mathrm{l}$. In 32 participants these events were in the time period between 23:00 and 06:00 (percentage of time range 2-100). More than half of patients had median fasting blood glucose level above $7.2 \mathrm{mmol} / \mathrm{l}$. A total of 18 participants had blood glucose level above $8.3 \mathrm{mmol} / \mathrm{l}$ in the time period between 23:00 and $06: 00$ for more than $50 \%$ of the time. Measured mean standard deviation was 1.9. Among patients with registered hypoglycemia, ten patients had monotherapy (nine of them were on metformin), 19 patients had dual therapy (58\% had metformin plus oral insulin secretagogues prescribed), and nine had triple therapy (56\% with metformin plus oral insulin secretagogues plus DPP4 inhibitor) prescribed. Only 12 patients registered subjective sense of hypoglycemia in their respective diaries.

With an almost $40 \%$ detection rate, more hypoglycemia than we suspected was found. Since there was no record of severe hypoglycemia and most hypoglycemia happened during the night, without use of CGM, these events would otherwise go unnoticed. In order to reduce the risk and fear of hypoglycemia, hypoglycemia unawareness, and hypoglycemic events, improved patient and physician education on optimal detection and understanding of hypoglycemia and the benefits of detailed blood glucose measurement, such as CGM, is needed [2]. Unexpectedly, about a quarter of patients with registered hypoglycemia were treated with metformin as monotherapy. Metformin does not usually cause hypoglycemia when administered as monotherapy. In those rare cases hypoglycemia was suspected to be caused by additional blood glucose-lowering effects of the angiotensin-converting enzyme inhibitor and the non-steroidal anti-inflammatory drug possibly combined with suboptimal nutrition and/ or too strong exercise [3].

We conclude that by using professional CGM to track patterns of glucose values in patients with T2DM in primary care offices it is possible to identify hypoglycemia unawareness, nighttime hypoglycemia, and fluctuations of glucose that would otherwise go unnoticed. In order to provide their patients with T2DM a treatment as individualized as possible, PCPs should embrace new technologies such as CGM.

\section{ACKNOWLEDGEMENTS}

Funding. We are grateful to the Association of Teachers in General Practice/Family Medicine in Croatia who funded the study and publication of this article. No Rapid Service or Open Access Fees were received by the journal for the publication of this article.

Authorship. All named authors meet the International Committee of Medical Journal Editors (ICMJE) criteria for authorship for this article, take responsibility for the integrity of the work as a whole, and have given their approval for this version to be published.

Disclosures. Valerija Bralić Lang and Maja Baretić have nothing to disclose.

Compliance with Ethics Guidelines. This article is based on previously conducted studies and does not contain any studies with human participants or animals performed by any of the authors.

Peer Review. Please note, contrary to the journal's standard single-blind peer review process, as a Letter to the Editor this article underwent review by a member of the journal's Editorial Board.

Open Access. This article is licensed under a Creative Commons Attribution-NonCommercial 4.0 International License, which permits any non-commercial use, sharing, adaptation, distribution and reproduction in any medium or format, as long as you give appropriate credit to the original author(s) and the source, provide a link to the Creative Commons licence, and indicate if changes were made. The images or other third party material in this article are included in the article's Creative Commons licence, unless indicated otherwise in a credit 
line to the material. If material is not included in the article's Creative Commons licence and your intended use is not permitted by statutory regulation or exceeds the permitted use, you will need to obtain permission directly from the copyright holder. To view a copy of this licence, visit http://creativecommons.org/licenses/by$\mathrm{nc} / 4.0 /$.

\section{REFERENCES}

1. Ajjan R, Slattery D, Wright E. Continuous glucose monitoring: a brief review for primary care practitioners. Adv Ther. 2019;36(3):579-96.
2. Riddle MC, Rosenstock J, Gerich J, Insulin Glargine 4002 Study Investigators. The treat-to-target trial: randomized addition of glargine or human NPH insulin to oral therapy of type 2 diabetic patients. Diabetes Care. 2003;26(11):3080-6.

3. Zitzmann S, Reimann IR, Schmechel H. Severe hypoglycemia in an elderly patient treated with metformin. Int J Clin Pharmacol Ther. 2002;40(3): 108-10. 